University of Nebraska - Lincoln

DigitalCommons@University of Nebraska - Lincoln

\title{
Comparison of different MODIS data product collections over an agricultural area
}

\author{
Alan J. Stern \\ Hydrology and Remote Sensing Laboratory, Beltsville Agricultural Research Center, USDA-ARS, Beltsville, \\ MD, Alan.Stern@ars.usda.gov \\ Paul C. Doraiswamy \\ Deceased - Formerly with Hydrology and Remote Sensing Laboratory, Beltsville Agricultural Research \\ Center, USDA-ARS, Beltsville, MD \\ E. Raymond Hunt Jr. \\ Hydrology and Remote Sensing Laboratory, Beltsville Agricultural Research Center, USDA-ARS, Beltsville, \\ $M D$
}

Follow this and additional works at: https://digitalcommons.unl.edu/usdaarsfacpub

Stern, Alan J.; Doraiswamy, Paul C.; and Hunt, E. Raymond Jr., "Comparison of different MODIS data product collections over an agricultural area" (2014). Publications from USDA-ARS / UNL Faculty. 1545. https://digitalcommons.unl.edu/usdaarsfacpub/1545

This Article is brought to you for free and open access by the U.S. Department of Agriculture: Agricultural Research Service, Lincoln, Nebraska at DigitalCommons@University of Nebraska - Lincoln. It has been accepted for inclusion in Publications from USDA-ARS / UNL Faculty by an authorized administrator of DigitalCommons@University of Nebraska - Lincoln. 


\title{
Comparison of different MODIS data product collections over an agricultural area
}

\author{
Alan J. Stern ${ }^{\mathrm{a} *}$, Paul C. Doraiswamy ${ }^{\mathrm{b}}$, and E. Raymond Hunt $\mathrm{Jr}^{\mathrm{a}}$ \\ ${ }^{a}$ Hydrology and Remote Sensing Laboratory, Beltsville Agricultural Research Center, Agricultural \\ Research Service, U.S. Department of Agriculture, Beltsville, MD 20705, USA; ${ }^{b}$ Deceased - \\ Formerly with Hydrology and Remote Sensing Laboratory, Beltsville Agricultural Research Center, \\ Agricultural Research Service, U.S. Department of Agriculture, Beltsville, MD 20705 USA
}

(Received 3 July 2013; accepted 30 October 2013)

\begin{abstract}
Standard data products from NASA's moderate resolution imaging spectroradiometer (MODIS) were available at launch (collection 3) and have undergone two revisions (collections 4 and 5) during the continuing Terra and Aqua missions. In 2000, a research project was conducted in large fields of corn and soybean to evaluate MODIS leaf area index (LAI) and land cover type (MOD15 and MOD12 data products, respectively) as input to crop yield models. Our objective was to compare collections 3, 4 and 5 with the ground data to determine data product improvement. Classification of land cover type for collections 3, 4 and 5 were similar to the USDANASS Cropland Data Layer. The collection 5 MOD15 LAI was considerably improved over earlier collections when the quality assurance flags indicated good LAI retrievals. Land surface reflectances (MOD09) of MODIS band 2 (near-infrared, 250-m) were used as inputs to an inversion of the scattering by arbitrarily inclined leaves (SAIL) model. Compared to the collection 5 MOD15 product, SAIL-derived LAI had approximately equal agreement with the field data and had less systematic bias in root mean square error (RMSE). MODIS data products were designed to address global scientific questions without reliance on ground data, whereas the SAIL model inversions required ground data for model inputs. The accuracy of MODIS observations was not limiting LAI accuracy for broadleaf crops; additional information from nonMODIS sources may be required for improved MOD15 LAI.
\end{abstract}

\section{Introduction}

Two important data sets for determining agricultural yields from remote sensing are crop type and leaf area index (LAI) (Maas 1988; Doraiswamy et al. 2003, 2004). The United States Department of Agriculture National Agricultural Statistics Service (USDA-NASS) have been producing the cropland data layer (CDL) annually for crop type starting with North Dakota in 1998 (Johnson and Mueller 2010; Boryan et al. 2011). In crop models, LAI may be used either as an input or as a validation measure (Maas 1988; Doraiswamy et al. 2003, 2004, 2005).

Since NASA Terra's launch on 18 December 1999, moderate resolution imaging spectroradiometer (MODIS) standard data products have had a series of revisions (Justice et al. 2002; Yang et al. 2006b). Collection 3 was available shortly after launch to April 2004, collection 4 was available from April 2004 to May 2008 and collection 5 has been available since May 2008. With each revision, the data acquired since launch

\footnotetext{
*Corresponding author. Email: Alan.Stern@ars.usda.gov
} 
were reprocessed and distributed. Two of the standard data products are land cover type (MOD12) (Friedl et al. 2002, 2010) and LAI (MOD15) (Yang et al. 2006b; Knyazikhin et al. 1998). The MOD15 algorithm requires the assigned land cover type from MOD12. There have been worldwide efforts to validate the data products (Doraiswamy et al. 2005; Yang et al. 2006b; Tan et al. 2005; Cohen et al. 2006; Rizzi et al. 2006).

Another method of retrieving LAI uses surface reflectance data in an inversion of the scattering by arbitrary inclined leaves (SAIL) model (Doraiswamy et al. 2005; Verhoef 1984; Jacquemoud et al. 2009; Le Maire et al. 2011). In 2000, Doraiswamy et al. (2005) assessed the standard data products, MOD09 and MOD12, for agricultural crops just after Terra's launch. They found LAI values during midseason were unrealistically high for broadleaf crops from the collection 3 LAI data product (Doraiswamy et al. 2005), which were also found by others (Tan et al. 2005; Rizzi et al. 2006). Our objective is to compare MOD15 LAI among the various collections and compare the MOD15 data product with LAI retrieved from SAIL model inversions of the MOD09 surface reflectance data products (Vermote et al. 1997).

\section{Methods}

\subsection{Study site and field data acquisition}

McLean County, Illinois, USA (Figure 1), is primarily corn (Zea mays) and soybean (Glycine max) agriculture with some riparian gallery woodlands, pastures, and the city of

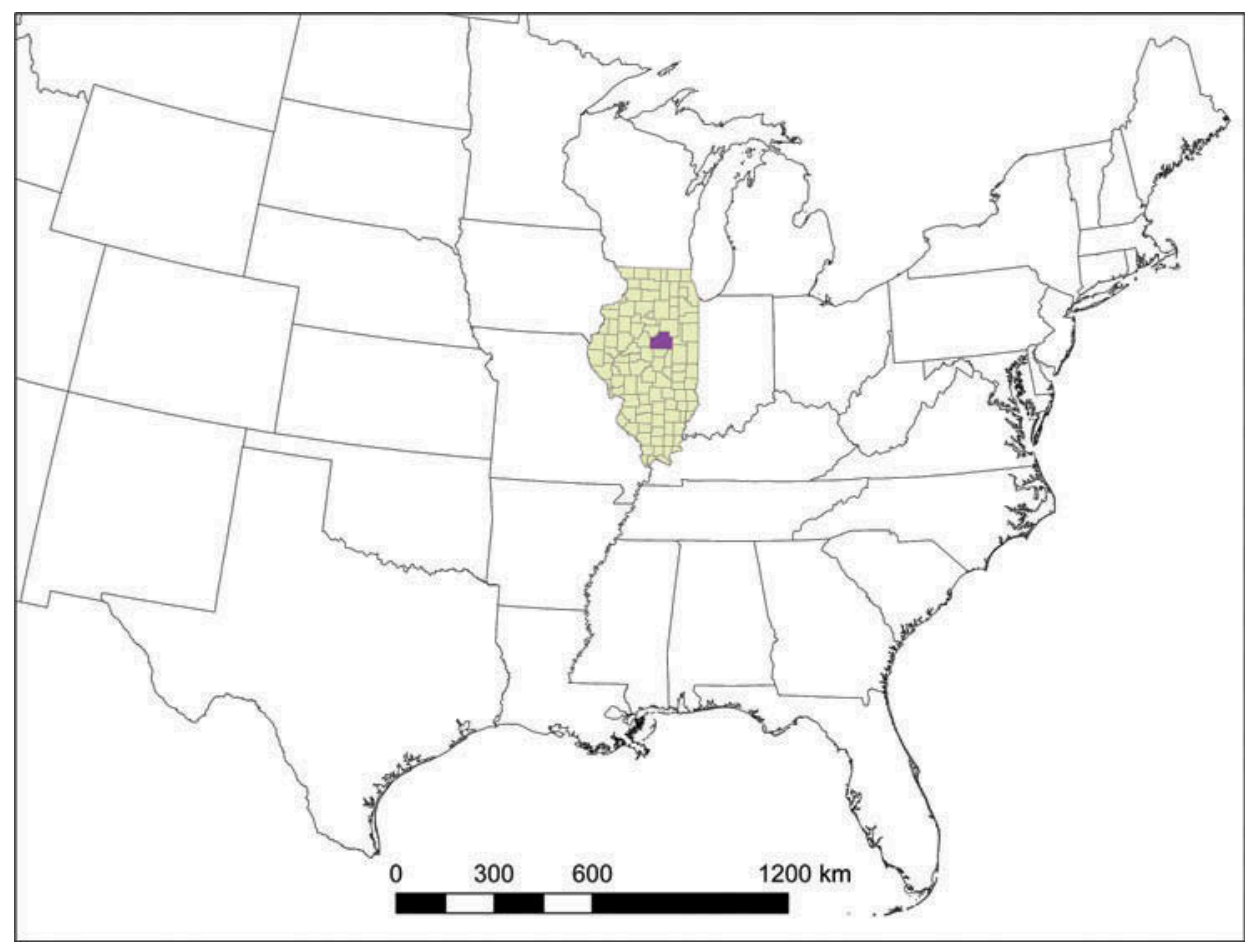

Figure 1. Location of McLean County, Illinois USA, a predominately corn-soybean agricultural area. 


\section{Legend

\begin{tabular}{l}
\hline Corn \\
\hline Urban \\
Forest \\
\hline Other grains \\
Pasture \\
Soybeans \\
Water \\
Wetlands
\end{tabular}

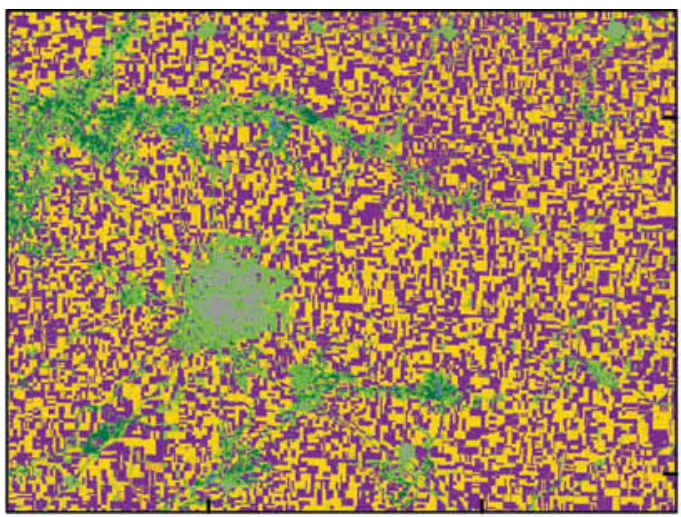

(a) $40^{\circ} 40^{\prime} 0^{\prime \prime} \mathrm{N}$

\section{Legend}

\begin{tabular}{l}
\hline Crop \\
Urban \\
Erbest \\
Fores \\
\hline$\square$ Mixed \\
Pasture \\
Water \\
Wetlands
\end{tabular}

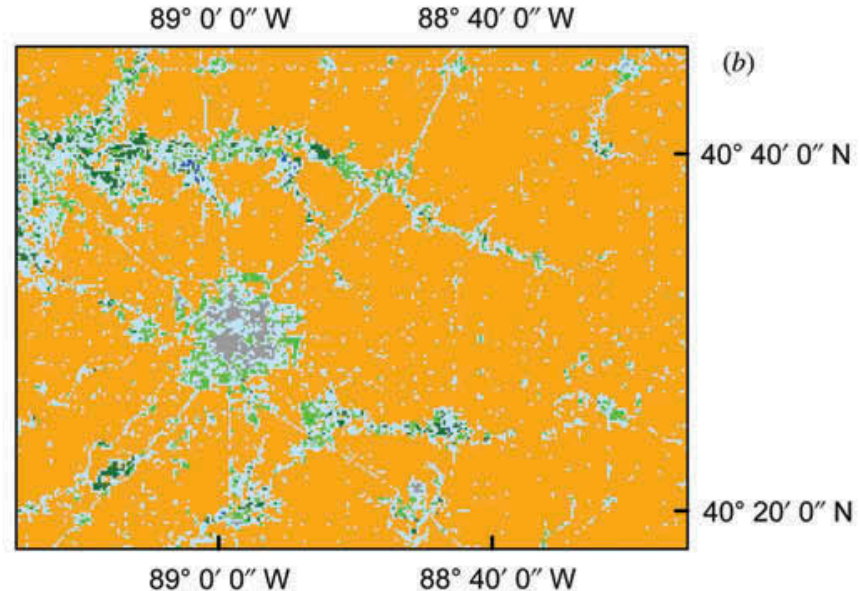

\section{Legend}

\begin{tabular}{|c|}
\hline Broadleaf crop \\
\hline Cereal crop \\
\hline Urban \\
\hline Forest \\
\hline Grassland \\
\hline Water \\
\hline Shrubs \\
\hline
\end{tabular}

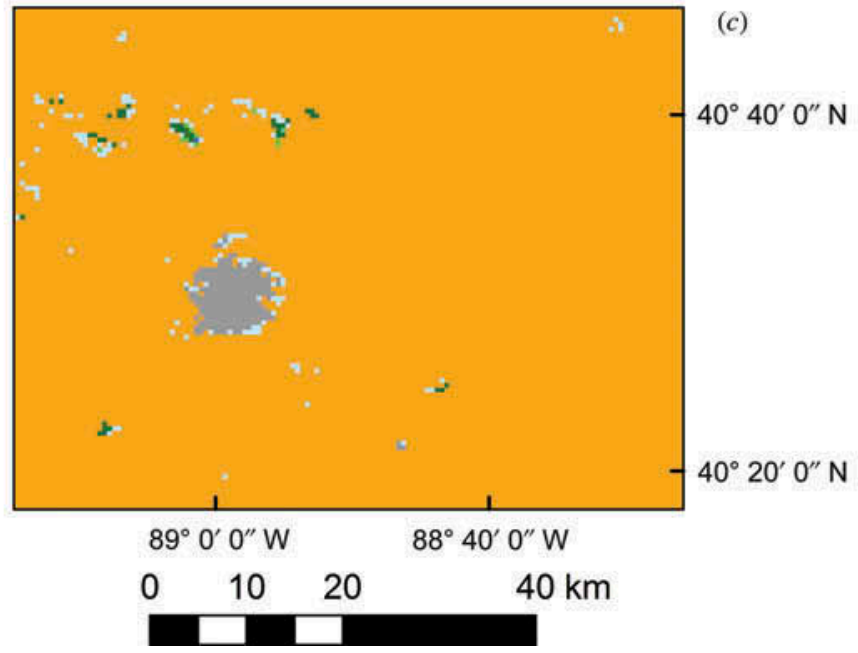

Figure 2. (a) The USDA-NASS CDL at 30-m resolution, (b) the CDL aggregated to $250 \mathrm{~m}$ and $(c)$ MODIS land cover type (MOD12, collection 5) at 500-m resolution.

Bloomington/Normal (Figure 2(a)). In 2000, 24 large fields of corn and soybean were selected based on major soil classes (Doraiswamy et al. 2005). Field measurements began in early June shortly after emergence and continued until late August on an approximately 
biweekly basis. Measurements of LAI were made with an LAI-2000 Plant Canopy Analyzer (LICOR, Inc., Lincoln, NE, USA). To minimize uncertainties in field data, each field visit consisted of taking at least 10 measurements in approximately the same location of the field. Soil reflectances and leaf reflectances and transmittances were measured with portable spectrometer (ASD Field Spec Pro FR, Analytical Spectral Devices, Inc., Boulder, CO, USA) coupled with an integrating sphere (LiCor Inc., LI1800-12).

There are many uncertainties in comparing field data and satellite imagery (Huang 2006), in part because field data may not be representative. A crop model was used to estimate LAI daily throughout the growing season based on planting date (Muchow, Sinclair, and Bennett 1990; Sinclair et al. 1997; Doraiswamy et al. 2005). A weighted LAI was calculated based on the percentages of corn and soybean.

\subsection{LAI and land cover data products}

In 2000, the USDA-NASS CDL for Illinois (USDA 2001) was created using Landsat 4 and 5 Thematic Mapper data at a resolution of $30 \mathrm{~m}$ (Figure 2(a)), which was then resampled to $250 \mathrm{~m}$ (Figure 2(b)). Soybean and corn were combined into one class; if the majority cover type was not greater than $75 \%$, the $250-\mathrm{m}$ pixel was classified as mixed (Figure 2(b)). MODIS land cover type (MOD12) tiles (h11v04, h11v05) for 2000 were downloaded at different times for collections 3 and 4 at a resolution of $1 \mathrm{~km}$ and collection 5 at a resolution of $500 \mathrm{~m}$. Collection 5 had land cover products available for 2001 only (Figure 2(c)); however, since the area is predominately broadleaf crops, almost all changes in land cover type were between types of broadleaf crops (rotations between corn and soybean). Land cover types were then resampled to $250-\mathrm{m}$ resolution. Differences among accuracy assessment matrices were tested for significance using $Z$ tests based on the kappa statistic (Congalton and Green 2009).

MODIS 8-day surface reflectances (MOD09) for Band 2 (near infrared) with a resolution of $250 \mathrm{~m}$ were acquired for 2000 for collections 4 and 5 (MOD09 collection 3 were not acquired while available online.). Band 2 reflectances for pixels in a single field were averaged and compared to field-based measurements that occurred within the 8day MODIS compositing period.

The MODIS 8-day LAI products (MOD15) were acquired at a resolution of $1 \mathrm{~km}$ for collections 3, 4 and 5. To reduce the obvious problem of comparing LAI derived from 250-m surface reflectances with a 1-km MOD15 LAI pixel, only MOD15 pixels that had at least 12 of 16 broadleaf crop pixels from the aggregated USDA-NASS CDL were used. The MODIS LAI data products were then resampled to $250 \mathrm{~m}$.

\subsection{SAIL model inversions for LAI from MODIS surface reflectance}

Estimation of LAI by SAIL model inversion was performed by masking out the MOD09 pixels that had less than either $75 \%$ corn or $75 \%$ soybean, based on the aggregated CDL (Figure 2(b)). The cut-off percentage for masking was important, if the value was set to low, more pixels were available, but the reflectance was not dominated by the crop of interest. If the cut-off percentage was set to high, there were too few pixels for analysis. Seventy-five per cent in this area resulted in a reasonable number of pixels, with good reflectance. We used a near-infrared reflectance of 0.45 and a transmittance of 0.53 for corn, and a reflectance of 0.50 and transmittance of 0.48 for soybean (Doraiswamy et al. 2005). Other key parameters were fixed; the soil background reflectance was 0.30 , and the 
leaf angle distribution was ellipsoid (appropriate for both corn and soybean) (Campbell 1990). Solar and view angles were determined by the date and time of the MODIS data acquisition. LAI was varied until the predicted and measured surface reflectances were equal.

LAI at 250-m resolution from model inversions and MOD15 were then compared with field measurements by averaging the pixel data for a single field and comparing the result to the field-based measurements that occurred within the 8-day period for the image. Analyses were done both using and ignoring quality assurance (QA) flags. Unfortunately, QA flags for collection 3 MOD15 LAI were not acquired while available online. Collection 4 MOD15 LAI data contained flags indicating extensive cloud cover during a large part of the growing season, even though the corresponding MOD09 QA flags did not indicate clouds. It was unclear why there was this discrepancy, although LAI values greater than 6.0 tended to be flagged as clouds in collection 4 .

Accuracies of SAIL model inversions with MOD15 LAI were determined using the root mean square error (RMSE). RMSE was divided into systematic and unbiased components based on the equations of Willmott (1982).

\section{Results and discussion}

\subsection{Land cover classification accuracy}

In the aggregated NASS CDL, cropland was $82 \%$ of the county area (Figure $2(b)$ ), followed by mixed pixels (majority class $<75 \%$ of $250-\mathrm{m}$ pixel). Pasture covered $3 \%$ of the county, and the remaining land cover types were $1 \%$ or less of the area. Thus, the overall accuracy assessment was dependent on accurate classification of cropland. MOD12 land cover from collections 3, 4 and 5 had overall accuracies of $94-95 \%$. Classification accuracies of the three collections were not significantly different, so only the assessment from the collection 5 was shown (Table 1). Pastures and woodlands were usually not correctly classified in MOD12 (Table 1); however, LAI was not compared for these classes. Thus, differences in land cover classification would not affect the LAI data product.

Table 1. Accuracy of MOD12 land cover type (collection 5) compared to USDA-NASS CDL. Overall accuracy is $95.1 \%$. Collections 3 and 4 cover types were not significantly different compared to collection 5 cover type.

\begin{tabular}{llrrrrrr}
\hline & \multicolumn{7}{c}{ CDL cover type (no. pixels) } \\
\cline { 2 - 8 } $\begin{array}{l}\text { MOD12 cover type } \\
\text { (no. pixels) }\end{array}$ & & Crop & Pasture & Urban & Water & Woodland & $\begin{array}{c}\text { User's } \\
\text { accuracy (\%) }\end{array}$ \\
& & 65,732 & 2357 & 112 & 22 & 744 & 95 \\
& Crop & 4 & 3 & 0 & 4 & 6 & 18 \\
& Pasture & 25 & 130 & 361 & 0 & 0 & 70 \\
& Urban & 0 & 0 & 0 & 1 & 0 & 100 \\
& Water & 14 & 5 & 0 & 7 & 75 & 74 \\
& Woodland & 100 & 0 & 76 & 3 & 9 & \\
& Producer's & & & & & & \\
& accuracy (\%) & & & & & & \\
\hline
\end{tabular}




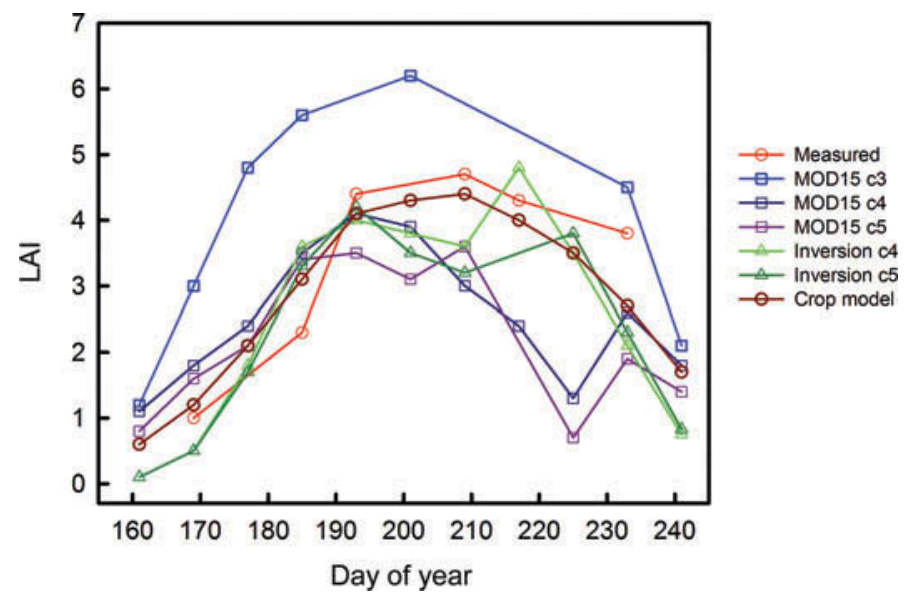

Figure 3. Average field-measured LAI for corn and soybean crops in McLean County, Illinois, over the 2000 growing season. Different LAI data products for the 2000 growing season were compared to the measurements: cropland-average MOD15 LAI from collections 3, 4 and 5 (MOD15 collection 3, MOD15 collection 4 and MOD15 collection 5, respectively); SAIL-model inversions using MOD09 surface reflectances from collections 4 and 5 (Inversion collection 4 and Inversion collection 5, respectively); and simulated LAI from a crop model.

\subsection{LAI comparisons}

Cropland-average MOD15 LAI from collection 3 was much higher compared to measured LAI for each day of the year (Figure 3). MOD15 LAI from collections 4 and 5 overpredicted LAI early in the growing season by about $65 \%$ and underpredicted LAI late in the growing season (Figure 3). Overall, MOD15 LAI values from collections 4 and 5 were much closer to the measured and simulated values. Inclusion of other cover types (particularly pasture) as cropland may have contributed to higher MOD15 LAI early in the growing season; however, with $82 \%$ of McLean County being cropland, the expected overprediction would have been closer to $20 \%$.

SAIL-model inversions (both collections 4 and 5) underpredicted LAI both early and late in the growing season (Figure 3). On day 185 and day 233, LAI from the crop model, MOD15 and SAIL-model inversions agreed with each other, but not measured LAI (Figure 3). From day 201-230, photosynthesis is required for grain filling, and LAI from SAIL-model inversions was much closer to measured and simulated LAI than was the MOD15 data product.

MOD15 LAI for collections 4 and 5 were linearly correlated with measured LAI (Table 2, Figure 4). The apparent decrease in MOD15 performance from collection 4 to collection 5 was caused by fewer points being excluded using the QA flags (Table 2). SAIL-model inversions from MOD09 collections 4 and 5 were also linearly correlated with measured LAI. However, the MOD15 data product had a higher intercept and lower slope compared to the SAIL-model inversions. This finding was similar to earlier work using the same field data (Doraiswamy et al. 2005).

MOD15 LAI collection 4 and 5 had a similar RMSE compared with the SAIL-model inversions of collection 4 and 5 data, respectively (Table 2). However, most of the errors in the MOD15 LAI data products are systematic, whereas most of the errors in the SAILmodel inversions are unbiased (Table 2). Globally, there is little bias in MOD15 LAI from 
Table 2. Accuracy of MODIS-derived LAI compared to measured LAI for collections 4 and $5^{*}$. All data are field averages. Some data were discarded based the MOD15 and MOD09 QA flags (QA-filtered). RMSE is divided into two components, systematic and unbiased (Willmott 1982).

\begin{tabular}{lccccc}
\hline & $\begin{array}{c}R^{2} \text { data } \\
\text { unfiltered(no. } \\
\text { points) }\end{array}$ & $\begin{array}{c}R^{2} \text { QA- } \\
\text { filtered (no. } \\
\text { points) }\end{array}$ & $\begin{array}{c}\text { Total RMSE } \\
\text { (QA-filtered) }\end{array}$ & $\begin{array}{c}\text { Systematic } \\
\text { RMSE (QA- } \\
\text { filtered) }\end{array}$ & $\begin{array}{c}\text { Unbiased } \\
\text { RMSE (QA- } \\
\text { filtered) }\end{array}$ \\
\hline $\begin{array}{l}\text { MOD15 LAI } \\
\text { collection 4 }\end{array}$ & $0.08(48)$ & $0.76(16)$ & 1.02 & 0.96 & 0.39 \\
$\begin{array}{c}\text { MOD15 LAI } \\
\text { collection 5 }\end{array}$ & $0.26(61)$ & $0.42(44)$ & 1.37 & 0.99 & 0.70 \\
$\begin{array}{c}\text { MOD09 } \\
\text { inversion LAI } \\
\text { collection 4 }\end{array}$ & $0.48(72)$ & $0.53(66)$ & 1.07 & 0.32 & 1.13 \\
$\begin{array}{c}\text { MOD09 } \\
\text { inversion LAI } \\
\text { collection 5 }\end{array}$ & $0.43(68)$ & $0.43(68)$ & 1.24 & 0.41 & 1.15 \\
\hline
\end{tabular}

Note: *MOD09 surface reflectances and QA flags for collection 3 MOD15 LAI were not acquired while available online.
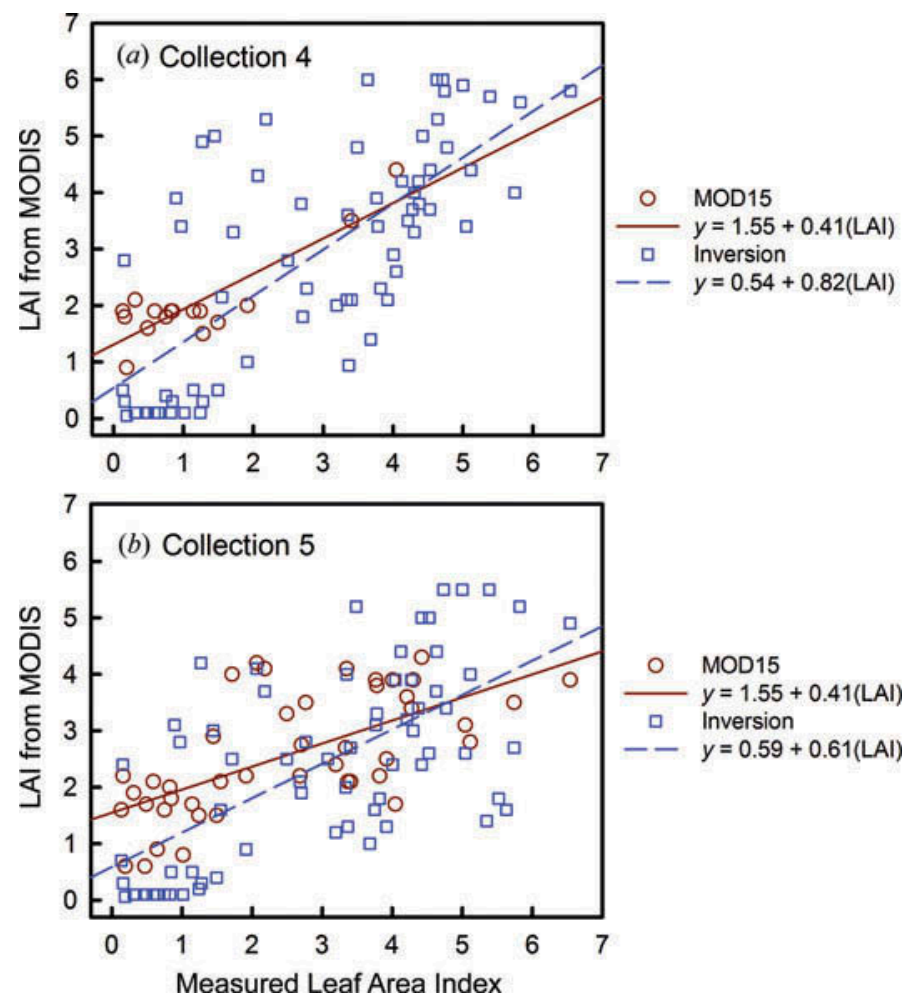

Figure 4. Field LAI measurements versus MOD15 LAI data product and SAIL-model inversions using MOD09 reflectances: $(a)$ collection 4 and $(b)$ collection 5. Each point is the average for a single field (24 fields) for the five dates when MODIS data coincided with field data collection. Data were filtered based on the QA flags for MOD15 and MOD09. 
collection 5 (Fang, Wei, and Liang 2012), so the bias in the MOD15 data product for broadleaf crops may be fixable with better retrieval parameters.

\section{Conclusions}

The MOD12 land cover data product did an excellent job when compared with the USDA-NASS CDL product in spite of the differences in spatial resolution. The accuracies did not change much among collections because the area was dominated by a single land cover class with two-year rotations between corn and soybean.

Collection 5 MOD15 LAI showed considerable improvement compared to both previous collections and LAI from SAIL-model inversions. MOD15 LAI was designed to be a global product without reliance on ground data, whereas the SAIL-model inversions required ground data for model inputs. Yang et al. (2006a) concluded that further improvement of the MODIS LAI product is mainly restricted to the accuracy of MODIS observations. We conclude that MODIS observations were accurate for broadleaf crops and were not the limiting factor for improved LAI. Instead, additional information from non-MODIS sources may be necessary for improved MOD15 LAI.

\section{Funding}

The work described in this letter was supported by the National Aeronautics and Space Administration grants to Dr Paul Doraiswamy (deceased).

\section{References}

Boryan, C., Z. Yang, R. Mueller, and M. Craig. 2011. "Monitoring US Agriculture: the US Department of Agriculture, National Agricultural Statistics Service, Cropland Data Layer Program." Geocarto International 26: 341-358.

Campbell, G. S. 1990. "Derivation of an Angle Density Function for Canopies with Ellipsoidal Leaf Angle Distributions." Agricultural and Forest Meteorology 49: 173-176.

Cohen, W. B., T. K. Maiersperger, D. P. Turner, W. D. Ritts, D. Pflugmacher, R. E. Kennedy, A. Kirschbaum, S. W. Running, M. Costa, and S. T. Gower. 2006. "MODIS Land Cover and LAI Collection 4 Product Quality Across Nine Sites in the Western Hemisphere." IEEE Transactions on Geoscience and Remote Sensing 44: 1843-1857.

Congalton, R. G., and K. Green. 2009. Assessing the Accuracy of Remotely Sensed Data Principles and Practices. 2nd ed. Boca Rotan, FL: CRC Press.

Doraiswamy, P. C., J. L. Hatfield, T. J. Jackson, B. Akhmedov, J. Prueger, and A. Stern. 2004. "Crop Condition and Yield Simulations Using Landsat and MODIS." Remote Sensing of Environment 92: 548-559.

Doraiswamy, P. C., S. Moulin, P. W. Cook, and A. Stern. 2003. "Crop Yield Assessment from Remote Sensing." Photogrammetric Engineering and Remote Sensing 69: 665-674.

Doraiswamy, P. C., T. R. Sinclair, S. Hollinger, B. Akhmedov, A. Stern, and J. Prueger. 2005. "Application of MODIS-Derived Parameters for Regional Crop Yield Assessment." Remote Sensing of Environment 97: 192-202.

Fang, H., S. Wei, and S. Liang. 2012. "Validation of MODIS and CYCLOPES LAI Products Using Global Field Measurement Data." Remote Sensing of Environment 119: 43-54.

Friedl, M. A., D. K. Mciver, J. C. F. Hodges, X. Y. Zhang, D. Muchoney, A. H. Strahler, C. E. Woodcock, et al. 2002. "Global Land Cover Mapping from MODIS: Algorithms and Early Results." Remote Sensing of Environment 83: 287-302.

Friedl, M. A., Sulla-Menashe, D., B. Tan, A. Schneider, N. Ramankutty, A. Sibley, and X. Huang. 2010. "MODIS Collection 5 Global Land Cover: Algorithm Refinements and Characterization of New Datasets." Remote Sensing of Environment 114: 168-182.

Huang, D., W. Yang, B. Tan, M. Rautiainen, P. Zhang, J. Hu, N. V. Shabanov, S. Linder, Y. Knyazikhin, and R. Myneni. 2006. "The Importance of Measurement Errors for Deriving 
Accurate Reference Leaf Area Index Maps for Validation of Moderate-Resolution Satellite LAI Products." IEEE Transactions on Geoscience and Remote Sensing 44: 1866-1871.

Jacquemoud, S., W. Verhoef, F. Baret, C. Bacour, P. J. Zarco-Tejada, G. P. Asner, C. François, and S. L. Ustin. 2009. "PROSPECT + SAIL Models: A Review of Use for Vegetation Characterization." Remote Sensing of Environment 113: S56-S66.

Johnson, D. M., and R. Mueller. 2010. "The 2009 Cropland Data Layer." Photogrammetric Engineering and Remote Sensing 76: 1201-1205.

Justice, C. O., J. R. G. Townshend, E. F. Vermote, E. Masuoka, R. E. Wolfe, N. Saleous, D. P. Roy, and J. T. Morisette. 2002. "An Overview of MODIS Land Data Processing and Product Status." Remote Sensing of Environment 83: 3-15.

Knyazikhin, Y., J. V. Martonchik, R. B. Myneni, D. J. Diner, and S. W. Running. 1998. "Synergistic Algorithm for Estimating Vegetation Leaf Area Index and Fraction of Absorbed Photosynthetically Active Radiation from MODIS and MISR Data." Journal of Geophysical Research 103: 32257-32276.

Le Maire, G., C. Marsden, W. Verhoef, F. J. Ponzoni, Lo Seen, D., A. Bégué, J. L. Stape, and Y. Nouvellon. 2011. "Leaf Area Index Estimation with MODIS Reflectance Times Series and Model Inversion During Full Rotations of Eucalyptus Plantations." Remote Sensing of Environment 115: 586-599.

Mass, S. J. 1988. "Use of Remotely-Sensed Information in Agricultural Crop Growth Models." Ecological Modeling 41: 247-268.

Muchow, R. C., T. R. Sinclair, and J. M. Bennett. 1990. "Temperature and Solar Radiation Effects on Potential Maize Yield Across Locations.” Agronomy Journal 82: 338-343.

Rizzi, R., B. F. T. Rudorff, Y. E. Shimabukuro, and P. C. Doraiswamy. 2006. "Assessment of MODIS LAI Retrievals Over Soybean Crop in Southern Brazil." International Journal of Remote Sensing 27: 4091-4100.

Sinclair, T. R., and Q. Bai. 1997. "Analysis of High Wheat Yields in Northwest China." Agricultural Systems 53: 373-385.

Tan, B., J. Hu, D. Huang, W. Yang, P. Zhang, N. V. Shabanov, Y. Knyazikhin, R. R. Nemani, and R. B. Myneni. 2005. "Assessment of the Broadleaf Crops Leaf Area Index Product from the Terra MODIS Instrument." Agricultural and Forest Meteorology 135: 124-134.

USDA National Agricultural Statistics Service. 2001. "USDA National Agricultural Statistics Service - Cropland Data Layer." Accessed May 8, 2013. http://nassgeodata.gmu.edu/CropScape

Verhoef, V. 1984. "Light Scattering by Leaf Layers with Application to Canopy Reflectance Modeling: The SAIL Model." Remote Sensing of Environment 16: 125-145.

Vermote, E. F., N. E. Saleous, C. O. Justice, Y. J. Kaufman, J. L. Privette, L. Remer, J. C. Roger, and D. Tanré. 1997. "Atmospheric Correction of Visible to Middle-Infrared EOS-MODIS Data Over Land Surfaces: Background, Operational Algorithm and Validation." Journal of Geophysical Research 102: 17131-17141.

Willmott, C. J. 1982. "Some Comments on the Evaluation of Model Performance." Bulletin of the American Meteorological Society 63: 1309-1313.

Yang, W., N. V. Shabanov, D. Huang, W. Wang, R. E. Dickinson, R. R. Nemani, Y. Knyazikhin, and R. B. Myneni. 2006a. "Analysis of Leaf Area Index Products from Combination of MODIS Terra and Aqua Data." Remote Sensing of Environment 104: 297-312.

Yang, W., B. Tan, D. Huang, M. Rautiainen, N. V. Shabanov, Y. Wang, J. L. Privette, et al. 2006b. "MODIS Leaf Area Index Products: From Validation to Algorithm Improvement." IEEE Transactions on Geoscience and Remote Sensing 44: 1885-1898. 